\title{
The Inefficiency of Ribosomes Functioning in Escherichia coli Growing at Moderate Rates
}

\author{
By ARTHUR L. KOCH \\ Department of Biology, Indiana University, Bloomington, Indiana 47405, U.S.A.
}

(Received 1 May 1979)

\begin{abstract}
It is generally agreed that ribosomes function with reduced efficiency (i.e. a smaller proportion is actually engaged in protein synthesis) in bacteria growing at low growth rates (doubling times greater than $2 \mathrm{~h}$ ). This paper examines whether the efficiency is constant in bacteria growing at various rates corresponding to doubling times of less than $2 \mathrm{~h}$. Because isotopic methods cannot be used in very rich media, turbidimetric methods have been extended to follow the kinetics of growth immediately following the shift-up of cultures of Escherichia coli ML308 growing in glucose minimal medium or succinate minimal medium into a very rich medium supporting a balanced doubling time of $17.4 \mathrm{~min}$. It is concluded that the efficiency of ribosome participation in protein synthesis is higher in the very rich medium than in the two minimal media, which support doubling times of 43 and $65 \mathrm{~min}$, respectively, at $37^{\circ} \mathrm{C}$.
\end{abstract}

\section{INTRODUCTION}

The 'constant efficiency' hypothesis of Maaløe \& Kjeldgaard (1966) has been a cornerstone of bacterial growth physiology. Originally it was postulated to account for changes in the composition of bacteria after nutritional shifts (Schaechter et al., 1958) and the composition of bacteria growing in media supporting different growth rates (Kjeldgaard et al., 1958; Neidhardt \& Magasanik, 1960). These results seemed to imply (Koch, 1968, $1970 a, 1971 b$; Maaløe \& Kjeldgaard, 1966) that the cell has primary control of its rate of synthesis of ribosomes and all the other components of the protein-synthesizing machinery. It appeared that this control operates in such a way that in the steady state the levels of components of the protein-synthesizing machinery would be such that the ribosomes working at high efficiency would just support the growth rate that the nutrient environment permitted. This implied that secondary control mechanisms operate to maintain the intracellular environment so that the efficiency with which an individual ribosome functions, and the fraction of the ribosomes actually engaging in protein synthesis, would be constant and maximal almost no matter what the steady-state growth conditions were. Subsequent work from our laboratory (reviewed in Koch, 1970 $a$, 1971 $a$, 1976), as well as later work from other laboratories (reviewed in Maaløe, 1979), showed that the efficiency was lower in very slowly growing cultures (doubling times $2 \mathrm{~h}$ or more) than in cultures growing at moderate to fast rates (doubling times in range $2 \mathrm{~h}$ to $30 \mathrm{~min}$ ). The present work shows that the efficiency of ribosomes in protein synthesis in Escherichia coli growing aerobically at $37^{\circ} \mathrm{C}$ at moderate rates ( 43 to $65 \mathrm{~min}$ doubling time) is less than that in cultures of bacteria growing very rapidly in rich complex media supporting a doubling time of $17 \cdot 4 \mathrm{~min}$. The relative efficiency was measured by turbidity measurements during shift-up experiments with a computer-linked double-beam spectrophotometer. 


\section{METHODS}

We have recently developed apparatus and techniques to increase the sensitivity and accuracy with which growth can be followed turbidimetrically (Wang \& Koch, 1978). The culture is contained in a special $10 \mathrm{~cm}$ flow cuvette system in which constant temperature water passes through the jacket and a stream of air bubbles aerate and circulate the culture in such a way that the air bubbles do not enter the light path. The system is contained in the cuvette compartment of a Cary model 16 double-beam spectrophotometer at constant temperature. The output from the spectrophotometer is fed into a Wang $720 \mathrm{C}$ mini-computer that corrects for deviation of the turbidity measurements from Beer's law and regresses the logarithm of the calculated dry weight concentration against time. Under steady state growth and under optimal conditions of growth rate and turbidity, the specific growth rate from 300 measurements taken during a $200 \mathrm{~s}$ period has a precision of better than $0.5 \%$.

Cultures of $E$. coli strain ML308 were grown with aeration at $37^{\circ} \mathrm{C}$ as described previously (Koch \& Coffman, 1970; Koch \& Deppe, 1971; Wang \& Koch, 1978). A sample (0.1 to $5 \mathrm{ml})$ was taken from a culture in balanced growth and immediately transferred to the growth cuvette system. The latter had previously been filled so that the final volume would be $40 \mathrm{ml}$ and equilibrated so that there would be no temperature shift. A period of $20 \mathrm{~s}$ was allowed for mixing before the growth measurements were started. [This time has been taken into account in the preparation of Fig. 1 and Table 1. The symbols in Fig. 1 have been placed at the midpoint of the $200 \mathrm{~s}$ measurement period.] Several factors may decrease the accuracy of the results during the initial period after a shift. These include (i) incompleteness of mixing, (ii) electrical transient in the photometer circuits caused by placing high voltage on the photomultiplier, (iii) the low initial growth rate and (iv) the low turbidities employed (when the kinetics of the shift were to be followed for several doublings). Nonetheless, the accuracy for the initial two $200 \mathrm{~s}$ periods was better than $10 \%$ in all experiments reported here.

The shift-up experiments were performed with bacteria previously grown for many doublings in M9 minimal medium containing either $0.02 \%$ succinate or $0.2 \%$ glucose under conditions where growth never slowed or stopped. The very rich shift-up medium, designated LBK-glu, consisted of the glucose-M9 medium plus $10 \mathrm{~g}$ tryptone $1^{-1}$ and $5 \mathrm{~g}$ yeast extract $\mathrm{l}^{-1}$. (These additions are the major ingredients and amounts present in Luria broth.) The glucose minimal medium supports a doubling time of 43 min, the succinate minimal medium $65 \mathrm{~min}$, and the shift-up medium $17 \cdot 4 \pm 1 \cdot 1 \mathrm{~min}$. The standard deviation of $1 \cdot 1 \mathrm{~min}$ reflects the day-to-day variation and is the standard deviation of means of the values obtained on individual days. The standard deviation of the runs made on any one day was smaller.

\section{RESULTS}

The response of bacteria from both glucose- and succinate-grown cultures to the shift-up environment was quite rapid (Fig. 1), occurring several minutes earlier than predicted by the theoretical curves drawn to fit the initial and final specific growth rates. These theoretical curves assume only that protein synthesis proceeds with the same efficiency in the pre- and post-shift media and that there is a $3 \mathrm{~min}$ lag in assembling a ribosome. The specific growth rate approached that of the steady-state cultures after long subculture on the shift-up medium with average half-times of 6.6 and $4.4 \mathrm{~min}$, respectively (see Table 1 for summary of experiments with the two media). The speed of the response was much greater than can be explained by the 'constant efficiency' hypothesis with any reasonable estimate of the mean maturation time for ribosomes (see Table 1).

It appears, therefore, that the growth rate increased faster than new ribosomes could be synthesized and assembled. This can be tested more critically, in a way which is independent of the detailed kinetics of ribosome maturation during the shift-up, by repeatedly measuring the specific growth rates in the first and second 200 s periods after a shift. Table 2 summarizes the results of three such series of experiments, on three separate days, in which sham shifts were interspersed with shifts to LBK-glu medium. This comparison shows that the initial increase was not an artifact of the photometry or of the computer treatment of the data. Thus the specific growth rate increased before ribosomes could possibly be matured at the higher rate established by the richer environment. Even in the second $200 \mathrm{~s}$ period the increase in total ribosomes in the cells must have been less than $5 \%$.

The initial rate of turbidity increase could reflect some osmotic changes or a change in 


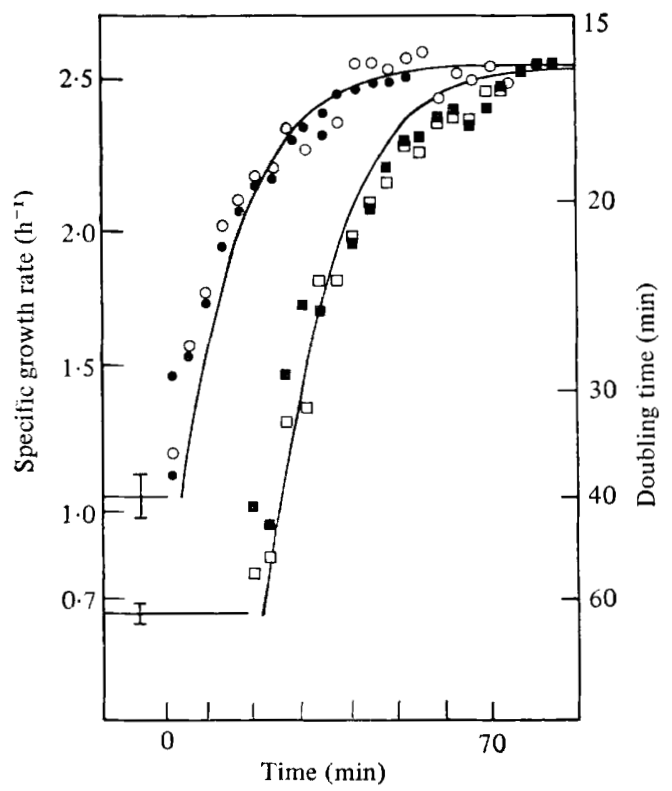

Fig. 1. Shift-up from glucose-M9 and succinate-M9 into LBK-glu. Growth kinetics measured in the computer spectrophotometer are shown. The instant of shift is indicated by the termination of the horizontal lines. The curves have been fitted to the 'constant efficiency' model with a 3 min lag for ribosome maturation (see Table 1). 0 and $\mathbf{0}$, Glucose-grown cultures; $\square$ and $\mathbf{\square}$, succinategrown cultures. (Open and closed symbols represent separate experiments carried out on different days.)

Table 1. Time for increase in specific growth rate to half-way between the pre-and post-shift values

\begin{tabular}{|c|c|c|}
\hline & $\begin{array}{l}\text { Glucose-M9 to } \\
\text { LBK-glu }\end{array}$ & $\begin{array}{l}\text { Succinate-M9 to } \\
\text { LBK-glu }\end{array}$ \\
\hline Experimental half-time* (min) & $6 \cdot 6 \pm 2 \cdot 8(5)$ & $4 \cdot 4 \pm 3 \cdot 7(4)$ \\
\hline $\begin{array}{l}\text { Theoretical half-time } \dagger \text { (min) } \\
\text { With no lag for maturation } \\
\text { With } 3 \text { min lagt }\end{array}$ & $\begin{array}{l}11 \\
14\end{array}$ & $\begin{array}{l}12 \\
15\end{array}$ \\
\hline
\end{tabular}

* The half-time values were estimated from experiments like those shown in Fig. 1; average values \pm standard deviations are shown, with the number of determinations in parentheses. The doubling time and specific growth rates under balanced growth conditions in the media are: LBK-glu, $17 \cdot 4 \pm 1 \cdot 14(7)$ min and $2 \cdot 39 \pm 0 \cdot 16 \mathrm{~h}^{-1} ; 0.2 \%$ glucose-M9, $40.3 \mathrm{~min}$ and $1.03 \mathrm{~h}^{-1} ; 0.02 \%$ succinate-M9, 68.1 min and $0.61 \mathrm{~h}^{-1}$.

$\uparrow$ The theoretical half-time values were calculated from the equation:

$$
\lambda=\lambda^{\prime} \frac{1-[(g-1) /(g+1)] \exp (-2 \lambda t)}{1+[(g-1) /(g+1)] \exp (-2 \lambda t)}
$$

derived by Koch $(1970 a)$. The specific growth rate before the shift is designated by $\lambda^{\prime}$, and that after the shift by $\lambda ; \lambda_{\max }$ is the steady-state growth rate in the new medium. The quotient of the steady-state specific growth rate in the shift-up medium to the preshift rate, $\lambda_{\max } / \lambda^{\prime}$, is $g$. The time measured from the time of the nutritional enrichment is $t$. The half-time value is the value of $t$ when $\lambda=\left(\lambda^{\prime}+\lambda_{\max }\right) / 2$. For the theoretical curves (Fig. 1) it is 0.63 and 0.69 of the doubling time in LBK-glu for bacteria previously growing in the glucose and succinate medium, respectively.

\$ The theoretical half-time values derived above were augmented by $3 \mathrm{~min}$. This is the smallest estimate of the mean time from initiation of rRNA synthesis to production of functional ribosomes (see text). 
Table 2. Initial response to shift-up

\begin{tabular}{|c|c|c|c|}
\hline & \multirow{2}{*}{$\begin{array}{c}\text { Expt } \\
\text { series* }\end{array}$} & \multicolumn{2}{|c|}{ Specific growth rate ${ }^{+}\left(\mathrm{h}^{-1}\right)$} \\
\hline & & First $200 \mathrm{~s}$ period & Second $200 \mathrm{~s}$ period \\
\hline $\begin{array}{l}\text { Sham shift } \\
\text { (succinate-M9 } \\
\text { to succinate-M9) }\end{array}$ & $\begin{array}{l}\mathrm{a} \\
\mathrm{b} \\
\mathrm{c}\end{array}$ & $\begin{array}{l}0.83 \pm 0.12 \\
0.81 \pm 0.16(7) \\
0.71 \pm 0.10\end{array}$ & $\begin{array}{l}0.64 \pm 0.03 \\
0.72 \pm 0.08 \\
0.71 \pm 0.10\end{array}$ \\
\hline $\begin{array}{l}\text { Shift-up } \\
\text { (succinate-M9 } \\
\text { to LBK-glu) }\end{array}$ & $\begin{array}{l}a \\
b \\
c\end{array}$ & $\begin{array}{l}1 \cdot 35 \pm 0.20 \\
0.98 \pm 0.14 \\
1 \cdot 27 \pm 0.31\end{array}$ & $\begin{array}{l}1 \cdot 25 \pm 0.17 \\
1 \cdot 34 \pm 0.21 \\
1 \cdot 59 \pm 0.24\end{array}$ \\
\hline
\end{tabular}

* Experiments of series $a, b$ and $c$ were run on three different days.

$\uparrow$ Mean values \pm standard deviation, with the number of determinations in parentheses.

Table 3. Effect of shift on non-protein-forming processes

\begin{tabular}{|c|c|c|c|c|}
\hline & & \multicolumn{3}{|c|}{ Specific growth rate $\left(h^{-1}\right)$} \\
\hline & & Pre-shift & Post-s & shift \\
\hline Minimal medium & $\begin{array}{l}\text { Expt } \\
\text { series* }\end{array}$ & $\begin{array}{l}\text { Minimal } \\
\text { medium }\end{array}$ & $\begin{array}{c}\text { Minimal } \\
\text { medium }+\mathrm{Cm}\end{array}$ & LKB-glu $+\mathrm{Cm}$ \\
\hline Glucose-M9 & $\begin{array}{l}\mathrm{a} \\
\mathrm{b}\end{array}$ & $\begin{array}{l}1.08 \\
0.96\end{array}$ & $\begin{array}{l}0 \cdot 57 \\
0 \cdot 48\end{array}$ & $\begin{array}{l}0.42 \\
0.22\end{array}$ \\
\hline Succinate-M9 & $\begin{array}{l}\mathrm{a} \\
\mathrm{b}\end{array}$ & $\begin{array}{l}0.66 \\
0.72\end{array}$ & $\begin{array}{l}0 \cdot 36 \\
0 \cdot 31\end{array}$ & $\begin{array}{l}0 \cdot 36 \\
0 \cdot 30\end{array}$ \\
\hline
\end{tabular}

* Experiments of series $a$ and $b$ were run on different days.

$\uparrow$ Specific growth rates were measured in the first $200 \mathrm{~s}$ after shift into media containing $500 \mu \mathrm{g}$ chloramphenicol $\mathrm{ml}^{-1}(\mathrm{Cm})$.

the rate of production of non-protein components of the cell triggered by the shift-up. While turbidity measurements respond primarily to increase in dry weight, and protein is the major cellular substance (about $80 \%$ ), other components do contribute to the turbidity. This possibility was tested (Table 3 ) in experiments where bacterial cultures were shifted either into the same minimal medium in which growth had taken place or into LBK-glu medium, both containing $500 \mu \mathrm{g}$ chloramphenicol $\mathrm{ml}^{-1}$. Since the primary target of this antibiotic is the ribosome, resulting in the blockage of protein synthesis, the difference between the means of the observed specific growth rates measures the effect not attributable to the rate of protein synthesis. It seems that such effects were small.

\section{DISCUSSION}

The experiments reported here involve an area of growth physiology which has been studied very little because complex media are needed to achieve rapid growth and this precludes reliable tracer experiments. These limitations do not apply to turbidimetric measurements. The theory is well understood (Koch, 1961, 1968, 1970b, 1980; Koch \& Ehrenfeld, 1968) for the light scattering of objects of the size and shape of bacteria and whose index of refraction differs little from that of their suspending medium. As long as the bacteria do not aggregate or grow filamentously, or become too large or too small, a well collimated photometer will yield a signal whose logarithm is accurately proportional to the concentration of dry mass. Additional considerations need to be made if the culture is synchronized, or if rod-shaped organisms become oriented in the light path, or if the culture is too dense. Up to an absorbance of $1 \cdot 1$, we have fitted a quadratic formula to correct for deviations from Beer's law and this yields the dry weight concentration of balanced cultures essentially independently of cell size. 
In our previous experimental work (Koch \& Deppe, 1971; Alton \& Koch, 1974), we measured the rate of protein synthesis before and after a nutritional shift-up by the incorporation of radioactive tryptophan into trichloroacetic acid insoluble material in short pulses. Tryptophan could be used because it was not a component of the shift-up medium, but this technique cannot be employed with complex media containing tryptophan peptides. In these studies, both the tracer technique and the turbidimetric studies of the lags before the establishment of the definitive growth rate in the shift-up media gave concordant results. Since it is now generally accepted that the efficiency is low in slowly growing cultures, this agreement supports the validity of the turbidimetric method.

The curves in Fig. 1 were calculated by the formula from Koch $(1970 a)$ given in the footnotes to Table 1. It is based on the assumption that at the time of the shift there is an instantaneous increase in the rate constant for the formation of rRNA. An alternative model is that of Bremer \& Dennis (1975) which assumes that the increase of rRNA instantly achieves the exponential growth rate characteristic of the new medium. This model predicts a slower increase for the specific growth rate of the culture than does the formula given in Table 1. If the Bremer-Dennis model were true an even greater increase in efficiency would be needed to account for the experimental findings.

In addition to a consideration of the kinetics of rRNA formation, a time lag must be introduced for the period needed for assembly and maturation of a functioning ribosome. In Fig. $1 \mathrm{I}$ have taken this to be $3 \mathrm{~min}$, much shorter than the original estimate of Mangiarotti et al. (1968), but consistent with Lindahl's (1975) kinetic determinations. He estimated $2 \%$ for the content of full length precursor forms of the total 23S type RNA and for the total precursor forms of total $16 \mathrm{~S}$ type RNA. This number implies a lag of $1.7 \mathrm{~min}$ for the synthesis of rRNA and an unknown time for the final assembly and maturation. Michaels (1972) measured the time between the addition of label and the appearance of radioactivity in the $70 \mathrm{~S}$ ribosomes in polysomes. Interpretation of his results is not clear, but for cells doubling every $30 \mathrm{~min}$ the time could be anything between 1.5 and $5 \mathrm{~min}$. I therefore assume that a negligible amount of new ribosomes can function to increase the rate of protein synthesis during the first or even the second $200 \mathrm{~s}$ measurement period.

The results in Fig. 1 and Tables 1 and 2 strongly imply that the 'constant efficiency' hypothesis in its original form does not hold for cultures in balanced growth in media supporting moderate specific growth rates. This means that either the number of ribosomes engaged in protein synthesis or the rate of synthesis of amino acid chains, or both, are increased very quickly after introduction of medium containing tryptone and yeast extract (and glucose). The first possibility, that succinate- or glucose-grown cells form more ribosomes than actually function under these conditions, is the more likely. This would be consistent with a progressive increase in the fraction of ribosomes actually engaged in protein synthesis as the specific growth rate increases in media of increasingly good nutrition. Unfortunately the shift experiments only measure the relative efficiency of the ribosomes in the pre- and post-shift media and do not yield an absolute efficiency. However, we have shown previously that the ribosomes of cells from carbon-limited chemostat cultures with a doubling time of 10 to $11 \mathrm{~h}$ function with 4.4 to 6.6 times the efficiency immediately after a shift to a rich medium (glucose, Casamino acids, vitamins) which supports a doubling time of $31 \mathrm{~min}$ (Koch \& Deppe, 1971). Similarly, we showed that the ribosomes of cells from phosphate-limited chemostat cultures with a doubling time of 8 to $12 \mathrm{~h}$ function with 6 to 9 times the efficiency when shifted to the same rich medium (Alton \& Koch, 1974). In the present experiments, it would appear that a $50 \%$ increase in efficiency would be sufficient to account for the observations of shifts of cultures with $43 \mathrm{~min}$ and $65 \mathrm{~min}$ doubling times to $17 \cdot 4$ min doubling time.

The concept that the fraction of ribosomes functioning in exponentially growing bacteria is a progressively increasing function of growth rate is consistent with cell fractionation studies in which ribosomes are measured separately from polysomes. In the critical and 
carefully executed studies of Harvey $(1970,1973)$ a linear relationship was found between this fraction and the specific growth rate in the range 0.25 to $1.25 \mathrm{~h}^{-1}$. Extrapolating his data, $20 \%$ of the ribosomes would function at zero growth rate and $100 \%$ would function at a specific growth rate of $1.8 \mathrm{~h}^{-1}$, corresponding to a doubling time of $23 \mathrm{~min}$. Harvey found that even in his richest medium (glucose-complete medium, equivalent to the rich medium of our previous studies) only $70 \%$ of the ribosomes were present in the cell in the form of polysomes, so the cells had the potential for a $30 \%$ increase in specific growth rate in a very short time. Interpolating from this data, instantaneous growth rate increases of $40 \%$ and $55 \%$ are possible for cells growing on glucose and succinate, respectively, if it is assumed that all ribosomes function in the very rich medium supporting a 17.4 min doubling time. Such an increase would be sufficient to account for the present experimental results.

Another possible interpretation of the experimental results is that the step time for mRNA synthesis and the coupled amino acid addition to the growing polypeptide chain decreases in this very rich medium below that occurring in bacteria growing in glucose- or succinateminimal media. However, it would be difficult to imagine that substrates for protein synthesis would be available internally in sufficiently large amounts to increase protein synthesis to greater than 48 nucleotides or 16 to 20 amino acids per second (see Maaløe, 1979; Dalbow \& Young, 1975).

The major conclusion to be drawn from these studies is that even when bacteria are growing in media supporting moderate growth rates, they make and hoard the machinery for protein synthesis and do not use this machinery to its full potential. If this has any evolutionary or ecological implications, it is that often in the past, conditions have changed for the better. In such circumstances organisms have adopted an optimistic strategy and developed or modified control mechanisms so that they do not respond solely to the ambient conditions; rather, they imprudently make, and then fail to use, cellular materials. This strategy lowers their fitness for the moment, but in the long run, if conditions improve often enough, it may increase their time-averaged fitness (Koch, 1971 $a, 1976$ ).

This work was supported by the Metabolic Biology Program of the NSF under grant BMS 72-01852 A03. I wish to thank Ms C. Houston Wang for superb technical assistance and Dr Robert Harvey for help and constructive criticism.

\section{REFERENCES}

Alton, T. H. \& Koch, A. L. (1974). Unused protein synthetic capacity of Escherichia coli grown in phosphate-limited chemostats. Journal of Molecular Biology 86, 1-9.

Bremer, H. \& Dennis, P. P. (1975). Transition period following a nutritional shift-up in the bacterium Escherichia coli $\mathrm{B} / \mathrm{r}$ : stable RNA and protein synthesis. Journal of Theoretical Biology 52, 365-383.

Dalbow, D. G. \& Young, R. (1975). Synthesis time of $\beta$-galactosidase in Escherichia coli as a function of growth rate. Biochemical Journal 150, 13-20.

HARVEY, R. J. (1970). Regulation of ribosomal protein synthesis in Escherichia coli. Journal of Bacteriology 101, 514-583.

HaRveY, R. J. (1973). Fraction of ribosomes synthesizing protein as a function of specific growth rate. Journal of Bacteriology 114, 287-293.

KJeldgaARd, N. O., MaAløe, O. \& Schaechter, M. (1958). The transition between different physiological states during balanced growth of Salmonella typhimurium. Journal of General Microbiology $19,607-616$.
KoCH, A. L. (1961). Some calculations on the turbidity of mitochondria and bacteria. Biochimica et biophysica acta 51, 429-441.

KocH, A. L. (1968). Theory of angular dependence of light scattered by bacteria and similar-sized biological objects. Journal of Theoretical Biology 18, 133-156.

KocH, A. L. (1970a). Overall controls on the biosynthesis of ribosomes in growing bacteria. Journal of Theoretical Biology 28, 203-231.

KoCH, A. L. $(1970 \mathrm{~b})$. Turbidity measurements of bacterial cultures in some available commercial instruments. Analytical Biochemistry 38, 252-259.

KocH, A. L. $(1971 a)$. The adaptive responses of Escherichia coli to a feast and famine existence. Advances in Microbial Physiology 6, 147-217.

KocH, A. L. $(1971 b)$. Evaluation of the biological processes from tracer kinetic data. IV. Digital simulation of nucleic acid metabolism in bacteria. Journal of Theoretical Biology 32, 451-469.

KocH, A. L. (1976). How bacteria face depression, recession, and derepression. Perspectives in Biology and Medicine 20, 44-63. 
KocH, A. L. (1980). Measurement of growth. In Manual of Methods for General Microbiology (in the Press). Washington, D.C.: American Society for Microbiology.

Koch, A. L. \& Coffman, R. (1970). Diffusion, permeation, or enzyme limitation: a probe for the kinetics of enzyme induction. Biotechnology and Bioengineering 12, 651-677.

Koch, A. L. \& DePPE, C. S. (1971). In vivo assay of protein synthesizing capacity of Escherichia coli from slowly growing chemostat cultures. Journal of Molecular Biology 55, 549-562.

Koch, A. L. \& Ehrenfeld, E. (1968). The size and shape of bacteria by light scattering measurements. Biochimica et biophysica acta 165, 262-273.

LINDAHL, L. (1975). Intermediates and time kinetics of the in vivo assembly of Escherichia coli ribosomes. Journal of Molecular Biology 92, 15-37.

MAALøE, O. (1979). Regulation of protein synthesizing machinery - ribosomes, rRNA, factors, etc. In Biological Control and Development, pp. 520-542. Edited by R. Goldberger. New York: Plenum Press.
MaAløe, O. \& KueldgaARd, N. O. (1966). Control of Macromolecular Synthesis. New York: W. A. Benjamin.

Mangiarotti, G., Apirion, D., Schlessinger, D. \& Silengo, L. (1968). Biosynthetic precursors of 30 s and 50s ribosomal particles in Escherichia coli. Biochemistry 7, 456-472.

Michaels, G. A. (1972). Ribosome maturation of Escherichia coli growing at different growth rates. Journal of Bacteriology 110, 889-894.

Neidhardt, F. C. \& MagasaniK, B. (1960). Studies on the role of ribonucleic acid in the growth of bacteria. Biochimica et biophysica acta 42, 99-116.

Schaechter, M., MaAløe, O. \& KJeldgaARd, N. O. (1958). Dependency on medium and temperature of cell size and chemical composition during balanced growth of Salmonella typhimurium. Journal of General Microbiology 19, 592-606.

WANG, C. H. \& KoCH, A. L. (1978). Constancy of growth on simple and complex media. Journal of Bacteriology 136, 969-975. 